\title{
Editorial
}

\section{An End and a Beginning}

\author{
Carl Folke $^{1}$ and $\underline{\text { Lance Gunderson }}^{2}$
}

\author{
When you come to the fork in the \\ road-take it. Yogi Berra.
}

We have come to a fork in the road for this journal. With this issue, we undergo a seemingly drastic transformation. We are changing the name of the journal from Conservation Ecology to Ecology and Society. The journal will continue, but with a new name and a new look.

Why such a change? The Resilience Alliance, which funds and publishes the journal, made an executive decision to change the name. This was not done lightly, but after many hours of discussion. The concensus issuing from those discussions was that the old name did not adequately capture the broad scope and content of the journal and did not do justice to the integrative nature of the scholarship that has been and will continue to be published in it. The old name attracted too many narrow conservation studies more suitable for other journals. The journal's new name better reflects its integrative content, and emphasizes the interplay and interdependence between society and ecological systems, on local to global scales.

\section{FROM CONSERVATION ECOLOGY}

Conservation Ecology has been very successfulit is global in reach, rigorous, has a large readership, and attracts a wide range of papers from several disciplines. When it began 8 years ago, taking advantage of the internet, the hope was to develop a rigorous scientific journal that would more rapidly and widely disseminate information. This new medium would decrease the time to publication, attract articles that would communicate beyond the limits of the printed page, and hold the line on rising subscription costs. Most of these original goals have been achieved. There are over 11000 subscribers worldwide and the latest impact factor of the journal is 3.9.

We have published eight volumes, with 17 issues, including special features that range far afield in subject matter:

Sustainability and Resilience in Boreal
Regions
Recent Advances in Ecological Theory
and Practice
Adaptive Management
Interactive Science Education
Promises and Risks of Genetically
Modified Crops
Integrated Natural Resource Management
Human Ecosystems: Toward the
Integration of Anthropology and
Ecosystem Sciences
Traditional Knowledge in Social
Ecological Systems (on going)
Urban Sprawl (on going)

And there are new special features in the pipeline that will focus on the interplay between social and ecological systems.

The current issue clearly illustrates the interplay between ecology and society. In the Regular Issue, there are several contributions focusing on land-use change and fragmented landscapes. Wade et al. (2003) develop a method for analyzing human-induced forest fragmentation of biomes at the global scale and find that the human fragmentation imprint is the lowest among boreal forests. Burnett et al. (2003) investigate the strong exploitation pressure and fragmentation that are currently taking place in the boreal forests of Russian Karelia and the implications for biodiversity. Schmidt and Jensen (2003) address human-driven habitat fragmentation and its relation to biodiversity. They argue that habitat fragmentation over the last 175 years has been a major selective force in determining body length among mammals in Denmark. Fragmentation caused by roads is a well-known 
phenomenon. In this context, Loucks et al. (2003) highlight the significance of roadless areas protected from timber extraction in the USA for biodiversity conservation, including large mammals such as the grizzly bear.

The challenges of restoring degraded lands are addressed by Nielsen et al. (2003) for oak barren and savanna sites in Wisconsin, USA. Their results indicate that a more active management of ecosystem structures is required. Good et al. (2003) illustrate, through an analysis of salmonid populations, the dangers of applying standardized protocols of species recovery to habitat restoration and of assuming quantitative relationships between habitat and organism, as such assessments may not match reality.

There are two papers focusing on vulnerability in social-ecological systems. Gowrie (2003) develops a vulnerability index for Tobago in the West Indies and finds that the indicators with the highest vulnerability scores were human induced and could be redirected by improved management. Using the "Entitlement" framework (Sen 1980) and the "Panarchy" model (Gunderson and Holling 2002), Fraser (2003) explores the conditions leading to the potato famine of the mid1800 s that killed or displaced $25 \%$ of the Irish human population. In this way, he combines social vulnerability with ecological fragility and presents lessons for contemporary agriculture. There are also four book reviews and a discussion section in the issue.

The special feature on Human Ecosystems, combining anthropology and ecosystem science has come to a close with the publication of the introduction to the issue by guest editors Thomas Abel and John R. Stepp. We hope that you willl enjoy the now complete set of contributions to this very interesting special feature.

There are two special features in progress. Five contributions have been published in the feature on Traditional Knowledge in Social-Ecological Systems, drawing on insights from indigenous cultures and combining science with local knowledge for improved ecosystem management. The interdependence and coevolution between culture and nature is highlighted throughout the issue. In their study of Apache ecological knowledge and cultural traditions, Long et al. (2003) illustrate the significance of traditions, social norms for collective action and adaptive management in freshwater and ecosystem restoration. The role of elders, as holders of social memory of local cultures, in understanding and managing ecosystem dynamics and learning adaptively for social-ecological resilience is analyzed by DavidsonHunt and Berkes (2003) through their collaboration with First Nations in Canada. Watson et al. (2003) argue that wilderness protection can help maintain opportunities to continue traditional relationships with nature for improved natural resource management in several countries of the circumpolar north.

Becker and Ghimire (2003) show how a selfgoverning community in Ecuador, interacting with conservation NGOs, curtailed destruction of their moist forest commons and water resources through learning and institutional flexibility. They demonstrate the potential in combining traditional institutions and local knowledge systems with scientific knowledge and practice for sustaining both ecosystem services and biodiversity. Milestad and Hadatsch (2003) describe a farming community in the Austrian Alps that manages a diverse traditional agricultural landscape for ecosystem services. Such communities are often made financially viable through support from higher levels of governance, but are vulnerable to structural changes, the erosion of ecological knowledge, and societal transformation. There are several other contributions to the special feature that will appear in the spring 2004 issue.

So far, there are three contributions published in the special feature on Urban Sprawl. From a complex systems perspective, they analyze the broader context of urban growth and urban-driven land-use change and its implications for ecosystem processes and biodiversity. In their analysis of ecoregions in the USA, Ricketts and Imhoff (2003) found that urban cover is positively correlated with both species richness and endemism; they conclude that conservation efforts in densely populated areas may be at least as important as preserving remote parks in relatively pristine regions. Allen and $\mathrm{Lu}$ (2003) develop a GIS-based integrated approach to modeling urban growth in terms of land-use change and use the model to predict future urban growth in the Charleston region of South Carolina through the year 2030. The Piedmont region of the southeastern USA is faced with uncontrolled urban and suburban sprawl. Conroy et al. (2003) raise cross-scale, resilience, and uncertainty issues derived from human impacts and urban growth on water resources and lotic systems in this region in the context of landscape-level decision making. There will be several additional papers published in this special feature in the spring of 2004. 


\section{TO ECOLOGY AND SOCIETY}

The new name-Ecology and Society: a journal of integrative science for resilience and sustainabilityreflects the objectives of the journal and captures the content of the majority of contributions that are published in the journal. We encourage submissions on topics relating to the ecological, political, and social foundations for resilient and sustainable socialecological systems over the short and long term, on scales ranging from local to global, and across scales.

We encourage contributions that treat humans as a part of and not apart from nature. Throughout history, humanity has shaped nature and nature has shaped the development of human society. We hope to fashion a journal that investigates a broad range of issues for a deeper understanding of linked ecological and social systems and the implications of such an understanding for management and policy.

We encourage contributions that move away from implicit assumptions of a biosphere in a global steady state to one founded on complex system thinking. It requires a shift from focusing on controlling change for optimal solutions to accepting that change and uncertainty are the rule rather than the exception. In the current situation of widespread ecological, social, economic, and political transformation, the luxury of living with a self-repairing and infinitely forgiving biosphere seems to be history. How can human society repair, strengthen, and increase the capacity of the biosphere to support and sustain social and economic development in the face of change? How can human society organize and develop along prosperous and desirable pathways or trajectories that enhance this capacity rather than erode it?

We solicit papers with interdisciplinary approaches and methods that are addressed in thoughtful and scholarly ways. We encourage publications that give equal treatment to multiple disciplines, not where one disciplinary approach subsumes another. We encourage papers that address the underlying foundations of science and sustainability.

As we are changing the name of the journal, we decided to review and revise the editorial board. There will be about 50 scientists on the editorial board, many having long experience in interdisciplinary work and scholarly backgrounds in disciplines ranging from the humanities and social sciences to ecology and the natural sciences.
After the new year, the website for Ecology and Society (www.ecologyandsociety.org) will become the primary site. Old issues of Conservation Ecology will be maintained and readily linked to the new website. (see the "About" section on the website www.consecol.org). We will continue to publish rigorous articles in the same areas covered in the past and, as before, published papers will be listed in a diversity of citation indexes.

We thank you for your interest in and support of Conservation Ecology and hope that you will join us on the new and exciting journey with Ecology and Society!

Responses to this article can be read online at: http://www.consecol.org/vol7/iss2/art13/responses/index.html

\section{LITERATURE CITED}

Allen, J., and K. Lu. 2003. Modeling and prediction of future urban growth in the Charleston region of South Carolina: a GIS-based integrated approach. Conservation Ecology 8(2): 2. [online] URL: http://www.consecol.org/vol8/iss2/art2.

Becker, C. D., and K. Ghimire. 2003. Synergy between traditional ecological knowledge and conservation science supports forest preservation in Ecuador. Conservation Ecology $\quad 8(1): \quad 1 . \quad$ [online] URL: http://www.consecol.org/vol8/iss1/art1.

Burnett, C., A. Fall, E. Tomppo, and R. Kalliola. 2003. Monitoring current status of and trends in boreal forest land use in Russian Karelia. Conservation Ecology 7(2): 8. [online] URL: http://www.consecol.org/vol7/iss2/art8.

Conroy, M. J., C. R. Allen, J. T. Peterson, L. J. Pritchard, and C. T. Moore. 2003. Landscape change in the southern Piedmont: challenges, solutions, and uncertainty across scales. Conservation Ecology 8(2): 3. [online] URL: http://www.consecol.org/vol8/iss2/art3.

Davidson-Hunt, I. and F. Berkes. 2003. Learning as you journey: Anishinaabe perception of social-ecological environments and adaptive learning. Conservation Ecology 8(1): $5 . \quad$ [online] URL: http://www.consecol.org/vol8/iss1/art5.

Fraser, E. D. G. 2003. Social vulnerability and ecological fragility: building bridges between social and natural sciences using the Irish Potato Famine as a case study. Conservation Ecology 7(2): 9. [online] URL: http://www.consecol.org/vol7/iss2/art9.

Good, T. P., T. K. Harms, and M. H. Ruckelshaus. 2003. 
Misuse of checklist assessments in endangered species recovery efforts. Conservation Ecology 7(2): 12. [online] URL: http://www.consecol.org/vol7/iss2/art12.

Gowrie, M. N. 2003. Environmental vulnerability index for the island of Tobago, West Indies. Conservation Ecology 7(2): $11 . \quad$ [online] URL: http://www.consecol.org/vol7/iss2/art11.

Gunderson, L., and C. S. Holling. 2002. Panarchy: Understanding Transformations in Human and Natural Systems. Island Press, Washington, D.C., USA.

Long, J., A. Tecle, and B. Burnette. 2003. Cultural foundations for ecological restoration on the White Mountain Apache Reservation. Conservation Ecology 8(1): 4. [online] URL: http://www.consecol.org/vol8/iss1/art4.

Loucks, C., N. Brown, A. Loucks, and K. Cesareo. 2003. USDA Forest Service roadless areas: potential biodiversity conservation reserves. Conservation Ecology 7(2): 5. [online] URL: http://www.consecol.org/vol7/iss2/art5.

Milestad, R. and S. Hadatsch. 2003. Organic farming and social-ecological resilience: the alpine valleys of Sölktäler, Austria. Conservation Ecology 8(1): 3. [online] URL: http://www.consecol.org/vol8/iss1/art3.

Nielsen, S., C. Kirschbaum, and A. Haney. 2003. Restoration of midwest oak barrens: structural manipulation or process-only? Conservation Ecology 7(2): 10. [online] URL: http://www.consecol.org/vol7/iss2/art10.

Ricketts, T. and M. Imhoff. 2003. Biodiversity, urban areas, and agriculture: locating priority ecoregions for conservation. Conservation Ecology 8(2): 1. [online] URL: http://www.consecol.org/vol8/iss2/art1.

Sen, A. 1980. Poverty and Famines. Clarendon Press, Oxford, UK.

Schmidt, N. M., and P. M. Jensen. 2003. Changes in mammalian body length over 175 years-adaptations to a fragmented landscape? Conservation Ecology 7(2): 6. [online] URL: http://www.consecol.org/vol7/iss2/art6.

Wade, T. G., K. H. Riitters, J. D. Wickham, and K. B. Jones. 2003. Distribution and causes of global forest fragmentation. Conservation Ecology 7(2): 7. [online] URL: http://www.consecol.org/vol7/iss2/art7.

Watson, A., L. Alessa, and B. Glaspell. 2003. The relationship between traditional ecological knowledge, evolving cultures, and wilderness protection in the circumpolar north. Conservation Ecology 8(1): 2. [online] URL: http://www.consecol.org/vol8/iss1/art2. 